\title{
Creep-Induced Microstructural Evolution and Acoustic Characterization in Tempered Martensitic Stainless Steel
}

\begin{abstract}
TOSHIHIRO OHTANI
The microstructural evolution of a tempered martensitic stainless steel (a 12 pct chromium steel, type-403), during creep test, subjected to a tensile creep test at $873 \mathrm{~K}$, was studied by monitoring the shear-wave attenuation and velocity using electromagnetic acoustic resonance (EMAR). The study disclosed an attenuation peak at around 20 to 30 pct of the creep life, and a minimum value at $50 \mathrm{pct}$ of the creep life, and a local minimum velocity at the attenuation peak, independent of the applied stress. These novel phenomena are interpreted as a result of microstructural changes, especially dislocation recovery. This interpretation is supported by transmission electron microscopy observations of the dislocation structure. The relationship between the changes in attenuation, velocity, and microstructure evolution can be explained with the string model. The study results have suggested that EMAR possesses the potential to assess the progress of creep damage and to predict the remaining creep life of metals.
\end{abstract}

DOI: $10.1007 / \mathrm{s} 11661-007-9232-4$

(C) The Minerals, Metals \& Materials Society and ASM International 2007

\section{INTRODUCTION}

AROUND the world, a great number of operating fossil, nuclear power, and petroleum plants were constructed during 1960s and 1970s and have exceeded the their original 30 - to 40 -year design life. ${ }^{[1,2,3]}$ Structural metals used in plant components subjected to complex service environments - for example, exposure to elevated temperatures or loading - undergo degradation of mechanical properties such as strength, fracture toughness, etc., due to microstructural changes, corrosion, fatigue, creep, and combinations of these. Creep is one of the most critical factors that determine the structural integrity of the components. To save energy, meet recent regulatory requirements for $\mathrm{CO}_{2}$ emissions, and improve thermal efficiency, steam pressures and operating temperatures in the components have been increased, resulting in accelerated material degradation. Furthermore, economic and environmental circumstances prohibiting the construction of new plants increase the severity of this problem. Nondestructive evaluation (NDE), which probes the characterization of microstructures, deformation and damage initiation, and growth, may play an essential role because of the growing awareness of the benefit of using NDE techniques to assess the performance of components. In particular, NDE is assuming greater significance in the assessment of material degradation. To operate plants safely past their design life, an NDE technique that enables the evaluation of the current state of materials and predicts their remaining life, has long been sought. ${ }^{[4-7]}$

TOSHIHIRO OHTANI, formerly Senior Researcher, with, Ebara Research Co., LTD, Fujisawa, Kanagawa, Japan, is Professor with the Shonan Institute of Technology, Department of Mechanical Systems Engineering, Fujisawa, Kanagawa 251-8511, Japan. Contact e-mail: ohtani@mech.shonan-it.ac.jp

Manuscript submitted August 21, 2006

Article published online July 3, 2007.
At present, surface replication, boat samples, and miniature test coupons are used to assess the creep damage after years of service. ${ }^{[1,8-11]}$ While somewhat successful, such tests are limited by restrictions associated with the considerable pretest knowledge required to determine the proper location for testing. In addition, these tests can be destructive in nature and considerable surface preparation may be required. Therefore, it is essential that a selected technique provide a measurement simple and quick enough to deal with a large number of objects and give accurate information about microstructural changes. A number of alternate methods for creep-damage evaluation are available for detecting the damage. Ultrasonic methods offer a unique way of evaluating the internal damage state with comparatively simple and easy instrumentation, while X-ray, replication, and measurements of hardness and magnetic properties merely inspect the surface or near-surface region of the metals.

The ultrasonic method has been extensively studied for assessing creep damage in a wide range of materials. ${ }^{[12-18]}$ In these studies, ultrasonic velocity, attenuation, and backscattering echoes of acoustic waves traveling through the materials have been measured with contacting piezoelectric transducers. Ultrasonic parameters, which are influenced by bulk material phenomena, can characterize microstructural changes, such as dislocation density, texture, and grain-size variation. In a few cases, the velocity changed more significantly than the attenuation. A sharp decrease in the velocity occurred after the formation of microcracks. In the early stages, however, a change in velocity did not reflect the damage progression, and the dislocations controlled the creep mechanism. Dislocation and microstructural change during creep caused attenuation changes. However, conventional contacting measurements cannot precisely reflect the creep damage, because 
excessive background noise obscures sensitivity to microstructural evolution. ${ }^{[19]}$ This problem is especially serious for attenuation measurement, because mechanical contacts allow the probing ultrasonic waves to propagate in the sample, as well as in the transducers, couplant, and buffer, where a significant fraction of the acoustic energy is absorbed during wave propagation. Therefore, noncontact measurement with electromagnetic acoustic transducers $(E M A T s)^{[20,21,22]}$ is preferable, but low transduction efficiency prevents us from accurately measuring the ultrasonic characteristics. To overcome this dilemma, we combined an EMAT with the resonant technique, so as to superimpose many signals coherently and compose large signal amplitudes. This is the electromagnetic-acoustic-resonance $(\text { EMAR })^{[20,21,22]}$ method developed for the contactless measurement of phase velocity and attenuation.

Previously, we studied the relationship between the microstructure and the ultrasonic properties, especially ultrasonic attenuation, with EMAR during creep in various metal materials. ${ }^{[23-28]}$ The results confirmed that an attenuation coefficient showed a peak at a specific time during the creep life and that the time does not depend on the stress and specimen shape.

The objective of this study is to assess the capability of the EMAR method in materials with more practical structures, to identify and assess ultrasonic attenuation and velocity during creep and to establish the relationship between the microstructural and the ultrasonic response. A tempered martensitic stainless steel of type403 was used for the sample. Martensitic stainless steels are essentially alloys of chromium and carbon that possess a body-centered tetragonal (bct) crystal structure (martensitic) in a hardened condition after being air cooled from the austenitizing temperature. They are ferromagnetic, hardened by heat treatments, and generally resistant to corrosion only in relatively mild environments. ${ }^{[2]}$ The most commonly used alloy within the martensitic stainless steel family is type-410, which contains $12 \mathrm{wt}$ pet $\mathrm{Cr}$ and $0.1 \mathrm{pct} \mathrm{C}$, to provide strength. Type-403 is similar to 410 , but the chemical composition is adjusted to prevent the formation of $\delta$ ferrite in heavy sections. It is used extensively for steamturbine rotor blades and gas-turbine compressor blades operating at a temperature of up to $753 \mathrm{~K} .^{[29]}$ In the present work, a bulk-wave EMAT ${ }^{[20,21,22]}$ was used to measure the ultrasonic attenuation and velocity in the thickness direction of specimens as creep progressed.

\section{EXPERIMENTS}

\section{A. Materials}

The material was taken from a commercial plate of tempered martensitic stainless steel (a 12 pct chromium steel, type-403). It was heated at $1253 \mathrm{~K}$ for 2 hours, water-quenched and heated at $1023 \mathrm{~K}$ for 2 hours, and tempered. Specimens for the creep test were machined as shown in Figure 1; the gage section was $5 \mathrm{~mm}$ thick, $18 \mathrm{~mm}$ wide, and $35 \mathrm{~mm}$ long. The rolling direction of the specimens was parallel to the longitudinal direction

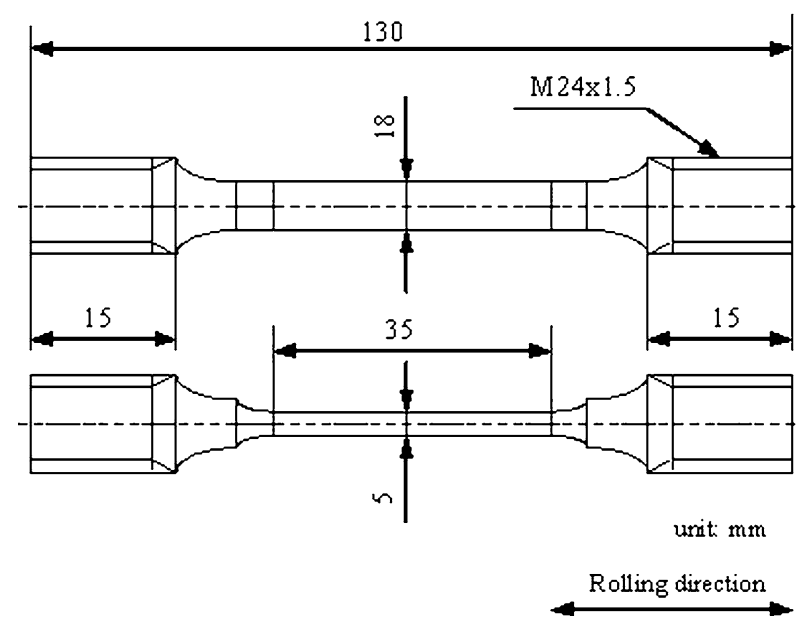

Fig. 1-Geometry and dimension of creep specimens in millimeters.

Table I. Chemical Composition of Type-403 (Weight Percent)

\begin{tabular}{lccccccc}
\hline $\mathrm{C}$ & $\mathrm{Si}$ & $\mathrm{Mn}$ & $\mathrm{P}$ & $\mathrm{S}$ & $\mathrm{Ni}$ & $\mathrm{Cr}$ & $\mathrm{Fe}$ \\
\hline 0.120 & 0.300 & 0.40 & 0.033 & 0.018 & 0.200 & 11.67 & bal \\
\hline
\end{tabular}

Table II. Mechanical Properties of Type-403 at the Room Temperature and $873 \mathrm{~K}$

\begin{tabular}{lcccc}
\hline & $\begin{array}{c}0.2 \text { Pct } \\
\text { Temp }\end{array}$ & $\begin{array}{c}\text { Ultimate Tensile Elongation } \\
\text { Proof }\end{array}$ & $\begin{array}{c}\text { Reduction } \\
\text { of Ares }\end{array}$ & Strength (MPa) \\
\hline RT & 562 & 720 & 25.0 & 73.9 \\
$873 \mathrm{~K}$ & 252 & 302 & 50.1 & 93.1 \\
\hline
\end{tabular}

of the specimens. The chemical composition and mechanical properties at room temperature (RT) and at $873 \mathrm{~K}$ are shown in Tables I and II, respectively.

\section{B. The EMAT}

We used a shear-wave EMAT with an active area $10 \times 10 \mathrm{~mm}$ in size, which was composed of an elongated-spiral coil and a pair of permanent magnets in opposite directions, normal to the specimen surface, as shown in Figure 2. In a noncontacting manner, the EMAT generated and received shear waves with the magnetostrictive effect of ferromagnetic materials. The polarized shear waves traveled back and forth in the thickness direction. For more details, see articles by Maxfield and Fortunko, ${ }^{[30]}$ Wilbrand, ${ }^{[31]}$ and Thompson. ${ }^{[32]}$

We measured resonant frequencies and attenuation coefficients for resonant modes with a superheterodyne spectrometer. ${ }^{[33]}$ The resonant peaks appear at equal frequency intervals and at each resonant frequency; the attenuation coefficient is measured by the free-decay method, leading to the frequency dependence of attenuation. ${ }^{[34]}$ 


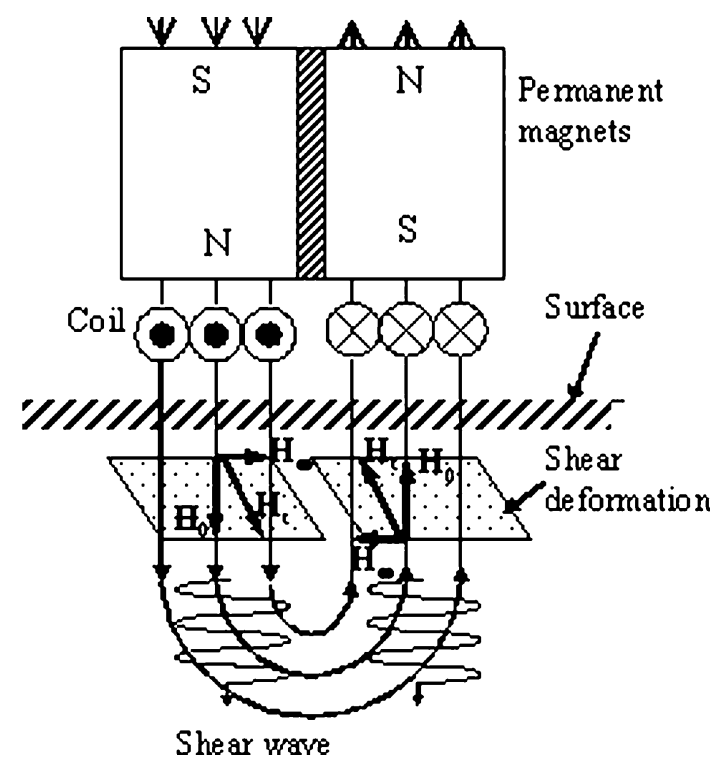

Fig. 2-Constitution and generation mechanism of the polarized shear wave by magnetostrictive effect. The $H_{0}, H_{\omega}$, and $H$ denote the bias field, the dynamic field, and the total field composed of the vector summation, respectively.

\section{Creep Tests}

Creep tests were carried out at $873 \mathrm{~K}$ in air for the three stresses of 120,140 , and $160 \mathrm{MPa}$, with lever-type equipment. Two different creep tests were conducted. They are referred to as (1) the continuous test and (2) the interrupted test. In the continuous test, we interrupted creep loading and furnace-cooled the samples. After measuring ultrasonic properties (attenuation coefficients and velocity), we restarted the creep test. We repeated this procedure every 50,100, and 200 hours until rupture. In the interrupted test, ten specimens were prepared for $120 \mathrm{MPa}$. The creep test was individually carried out until the creep strain reached a target value. After the creep tests, ultrasonic properties were measured. The interrupted test provided us with a series of samples with different strains after the creep tests. We examined the unstressed samples alongside the creep samples to distinguish the effects of thermal history alone.

The continuous test provided measurements similar to those used in the field for periodic monitoring of the damage evolution in the same sample as creep progresses. The interrupted test was conducted to make a thorough investigation of the relationship between the microstructural evolution and the change in ultrasonic properties as the creep progressed, though there is some possibility that the test results are affected by sample-tosample variation.

We observed the microstructures of the specimens in the interrupted test with an optical microscope (OM), a field-emission scanning electron microscope (FE-SEM), and a transmission electron microscope (TEM). The TEM foils were made as follows: small disks $(3 \mathrm{~mm}$ in diameter) were cut out of the specimens; these were mechanically polished down to a thickness of $0.1 \mathrm{~mm}$ and then thinned using a standard electrolytic double jet

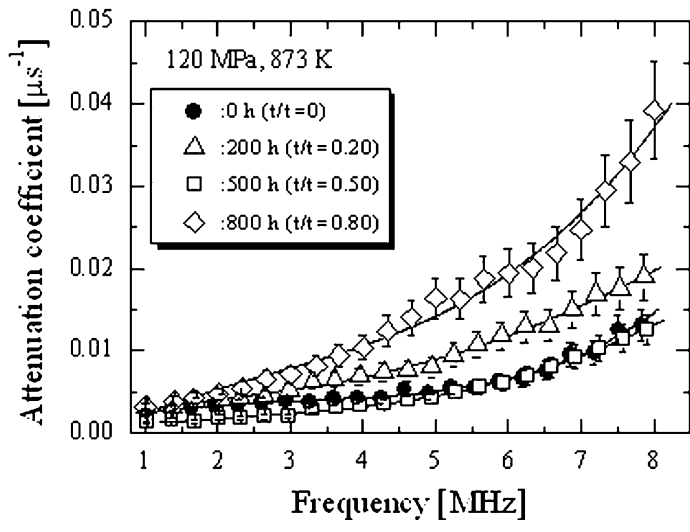

Fig. 3-Frequency dependence of the attenuation coefficient, $\alpha$, in the continuous test $(873 \mathrm{~K}, 120 \mathrm{MPa})$. The polarization is parallel to the stress direction.

technique. As an electrolyte, a 10 pct phosphoric acidethanol was used at $243 \mathrm{~K}, 40 \mathrm{~V}$, and $150 \mathrm{~mA}$. A TEM operating at $250 \mathrm{kV}$ was used to study the microstructure around the thinnest parts. The thickness in visible regions varied between 0.1 and $0.3 \mu \mathrm{m}$, which was measured by the convergent-beam electron diffraction (CBED) method. A mean thickness of $0.2 \mu \mathrm{m}$ was used for most of the calculations. The micrographs were scanned into a computer for further analysis. We also measured the Vickers hardness of the specimens. The measurement conditions were as follows: a load of 0.98 $\mathrm{N}$ and a holding time of 20 seconds.

\section{RESULTS}

\section{A. Continuous Test}

We measured the resonant frequencies in the 1- to 8-MHz range and their attenuations during the continuous test. Figure 3 displays the frequency dependence of the attenuation $\alpha$ at the life fraction $t / t_{r}$ (creep time/ rupture life) $=0,0.2,0.51$, and 0.80 . The rupture life was 990.6 hours. The stress was $120 \mathrm{MPa}$ and the polarization of the shear wave was parallel to the stress. We observed that $\alpha$ always increases with the resonant frequency, but the feature changes in the course of the creep advance.

Figure 4(a) shows the typical relationship between the attenuation coefficient $\alpha$, the relative velocity, $\Delta V / V_{i}$ $\left(V_{i}\right.$ : initial velocity), creep strain, creep-strain rate, and $t / t_{r}$ as creep progresses. The stress was $120 \mathrm{MPa}$ and the resonant mode was the 14th resonant mode around 4.5 MHz. The attenuation coefficient increases, showing a peak at $t / t_{r}=0.2$, then decreases, showing a minimum near $t / t_{r}=0.5$, and finally increases until failure. The velocity gradually decreases and shows a local minimum at the attenuation peak, then increases slightly until the attenuation minimum, and finally quickly decreases to the rupture. The total decrease in velocity was about 0.3 pct. The creep strain, however, monotonously increased until the rupture. The creep-strain rate rapidly decreased from the beginning to $t / t_{r}=0.2$, then 


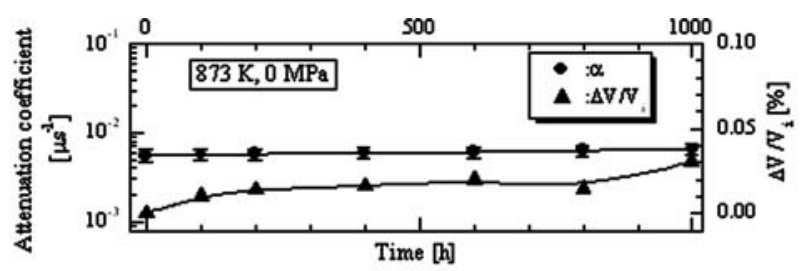

(b)

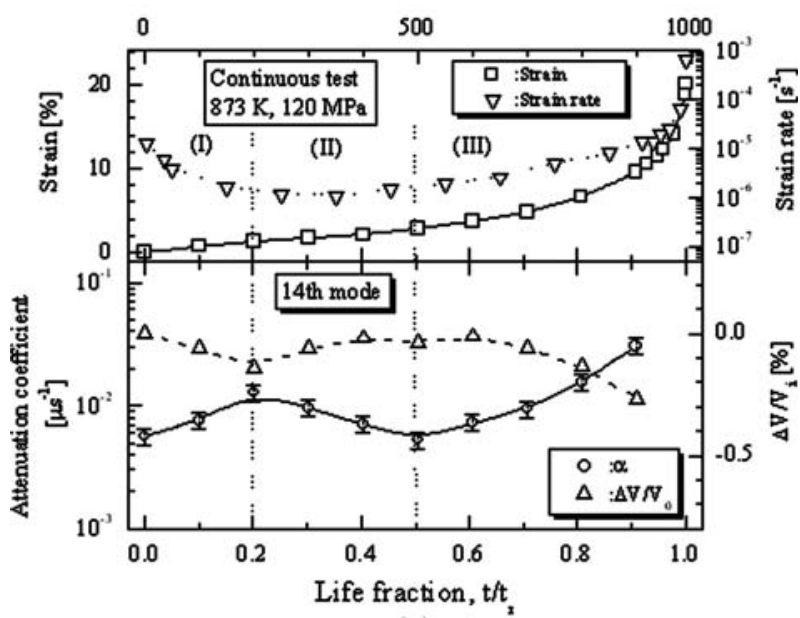

(a)

Fig. 4 - Relationship between $\alpha,\left(\Delta V / V_{i}\right.$, creep strain, strain rate, and $t / t_{r}$ at the 14th resonant mode $(\sim 4.5 \mathrm{MHz})$ of the crept sample $((a)$ $120 \mathrm{MPa}, 873 \mathrm{~K}$ in the continuous test) and reference sample $((b)$ stress free, $873 \mathrm{~K}$, until $1000 \mathrm{~h}$ ). The rupture life of crept sample was $990.6 \mathrm{~h}$. The shear wave polarization was parallel to the stress direction.

remained nearly unchanged until $t / t_{r}=0.5$, and finally quickly increased to the rupture. Only insignificant changes to the attenuation and velocity, as shown in Figure 4(b), were caused by the heat treatment, indicating that the changes in the ultrasonic properties are uniquely caused by creep.

Shown in Figure 5 are the evolution of the attenuation coefficient, velocity, and creep-strain rate under three different stresses $(120,140$, and $160 \mathrm{MPa})$. The resonant mode was the 11 th resonant mode around 3.5 MHz. The rupture lives were 1077.3 hours for $120 \mathrm{MPa}, 1040.4$ hours for $140 \mathrm{MPa}$, and 365.5 hours for $160 \mathrm{MPa}$. The evolutions of $\alpha$ and the velocity were commonly observed under the different stresses, showing clearly that evolution was not strongly independent upon the stress and other resonant modes.

\section{B. Interrupted Test}

Shown in Figure 6 is the relationship between the creep strain reached and the creep time. Each point corresponds to a separate specimen. The poor correlation between the strain and the time indicates that the creep damage is not solely dependent upon time. Thus, service time is an unsuitable measure of remaining creep life.

We applied the modified $\theta$ projection $^{[35]}$ and the fracture parameter $\mathrm{P}_{\alpha},{ }^{[36]}$ to estimate the life and the life

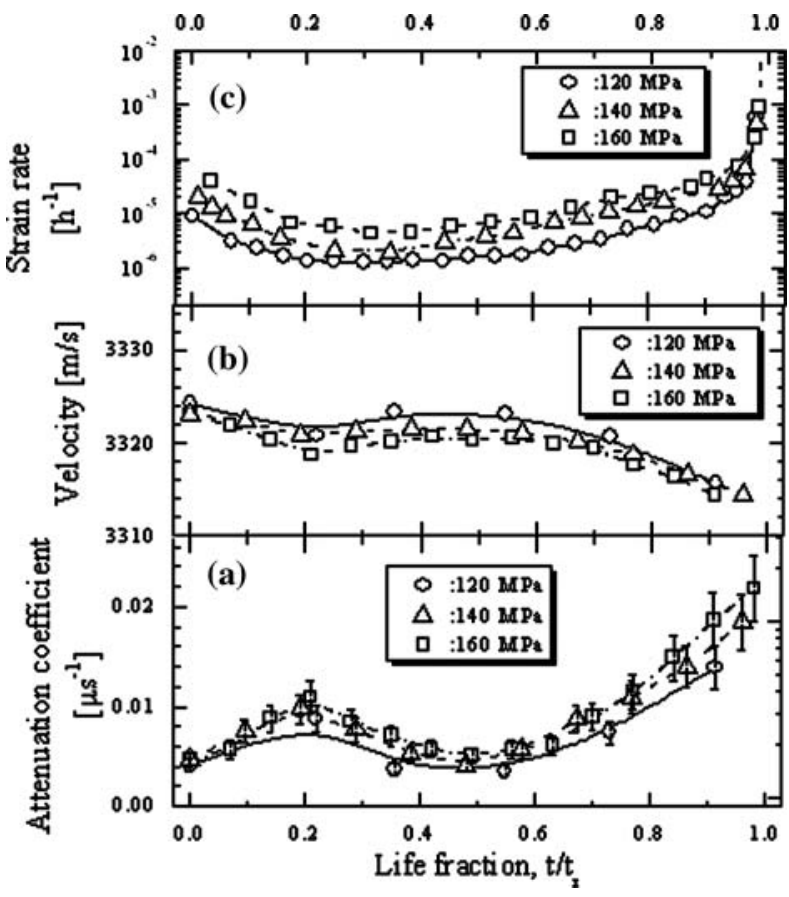

Fig. 5-Relationship between $\alpha$, velocity, creep-strain rate at the 11 th resonant modes $(\sim 3.5 \mathrm{MHz})$ and life fraction $(120,140$, and $160 \mathrm{MPa}, 873 \mathrm{~K})$ in the continuous test. The shear wave polarization is parallel to the stress direction. Rupture life $t_{r}=1077.3 \mathrm{~h}$ for $120 \mathrm{MPa}, t_{r}=1040.4 \mathrm{~h}$ for $140 \mathrm{MPa}$, and $t_{r}=365.5 \mathrm{~h}$ for $160 \mathrm{MPa}$.

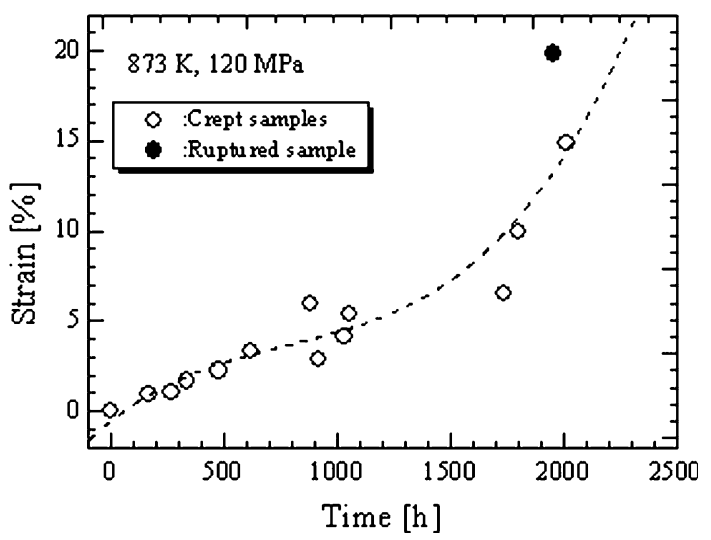

Fig. 6 - Creep curves in the interrupted test (120 MPa, $873 \mathrm{~K})$.

fraction of each sample. Figure 7 shows the resultant relationship between $t / t_{r}$ and the creep strain at $120 \mathrm{MPa}$, which is expressed with a single curve. Figure 8 displays the relationship among the evolutions of the ultrasonic properties, strain, and strain ratio, which shows the same trends as observed in the continuous test (Figure 4(a)), confirming the correctness of the predicted life ratio. Therefore, by observing the microstructures of the specimens in the interrupted test, we can discover what influenced the attenuation evolution and velocity as creep progressed. 


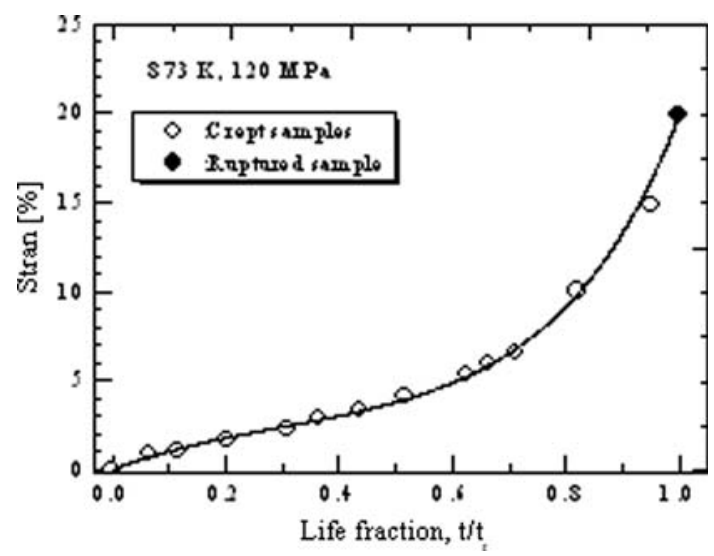

Fig. 7-Creep strain reached $v s$ estimated life fraction in interrupted test (120 MPa, $873 \mathrm{~K})$.

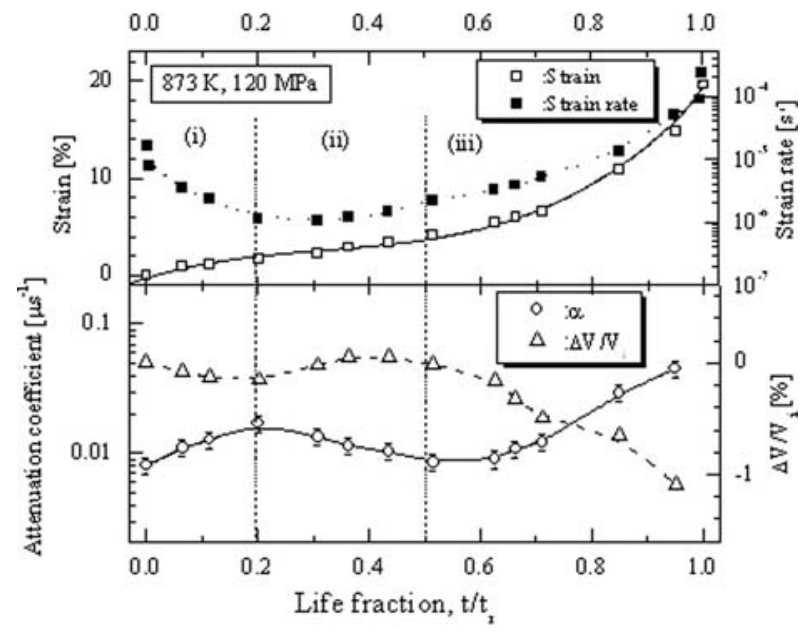

Fig. 8-Relationship between $\alpha,\left(\Delta V / V_{i}\right.$, creep strain, strain rate, and $t / t_{r}$, at the 14 th resonant mode under $120 \mathrm{MPa}$ in the interrupted test.

\section{Microstructure}

The following metallographic factors cause material deterioration from creep: ${ }^{\text {37-40] }}$

(a) precipitation and coarsening of carbides, ${ }^{[38]}$

(b) nucleation and development of voids, ${ }^{[39]}$ and

(c) recovery of dislocations (rearrangement and annihilation). ${ }^{[37,40]}$

From these points of view, we observed microstructure changes as creep progressed. No void was observed except in ruptured samples. Shown in Figures 9 and 10 are OM and SEM micrographs for the specimens at $t / t_{r}=0$ and 0.52 . The direction of stress was the horizontal direction of the photographs. The prior austenite grain boundaries and lath structure are observed in the micrographs in Figure 9. Fine precipitates are visible on prior austenite grain boundaries and lath boundaries in Figure 10. The precipitates (the arrow in Figure 10) were analyzed with energy-dispersive X-ray spectroscopy (EDX) and iden-

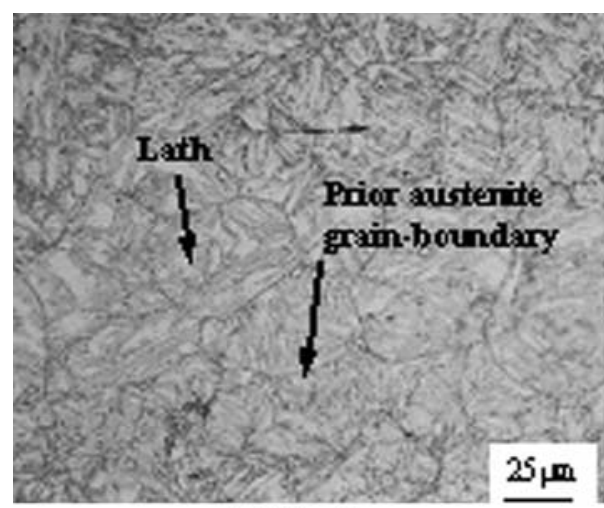

(a) $t / t=0$

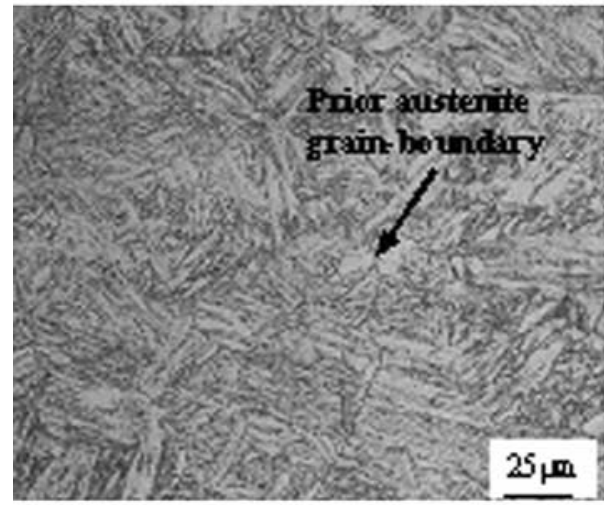

(b) $t / t_{t}=0.52$

Fig. 9-Optical micrographs of crept specimens at $t / t_{r}=0$, and 0.52 in the interrupted test (120 MPa, $873 \mathrm{~K})$.

tified as chromium-molybdenum carbides, which were assumed to be those with the general formula $\mathrm{M}_{23} \mathrm{C}_{6}{ }^{[41]}$ Shown in Figure 11 are the results obtained by analyzing these micrographs in the computer. On the assumption that oval precipitates are randomly distributed in the matrix, a volume value $V_{p}\left(\mu \mathrm{m}^{3}\right)$ of precipitate was calculated according to Eq. [1], ${ }^{[42]}$ which represents the volume of regular ellipsoid precipitates with $D_{\max }$ as the long axis and $D_{\min }$ for both small axes:

$$
V_{p}=4 / 3 \pi D_{\max } D_{\min }^{2}
$$

The results for the (heat-affected) reference sample and the ruptured sample are also shown. The size of the prior austenite grain boundary slightly increases as creep progresses (Figure 11(a)). Between the start of creep and $t / t_{r}=0.2$, the volume of the precipitates remains relatively constant or reduces slightly, while the number density decreases slightly. Until $t / t_{r}=0.6$, the volume increases gradually and the number density decreases by degrees. After that, both remain constant. In the reference sample, the changes in volume and number density were small. Thus, the applied stress strongly affected the coarsening and coalescence of precipitates, due to the increased dislocation density providing high diffusivity paths. 


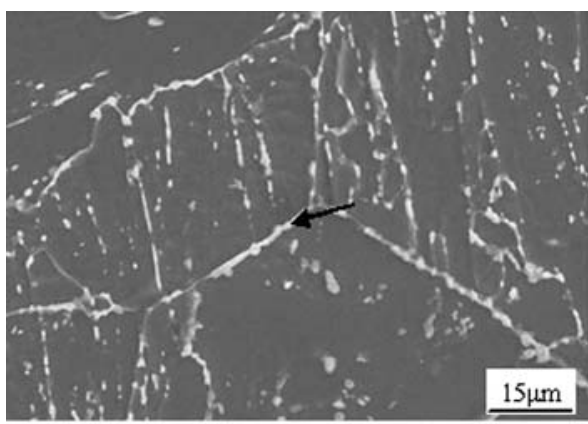

(a) $t / t_{r}=0$

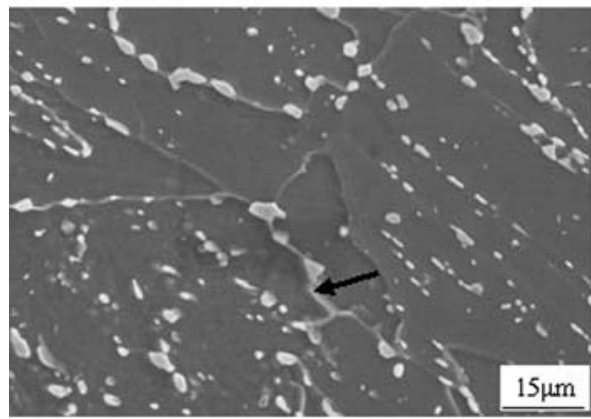

(b) $\mathrm{t} / \mathrm{t}_{\mathrm{r}}=0.52$

Fig. 10-SEM micrographs of crept specimens at $t / t_{r}=0$, and 0.52 in the interrupted test (120 MPa, $873 \mathrm{~K})$.

Figure 11(c) shows the Vickers hardness evolution. The hardness of the reference sample is also shown. The hardness decreased with an increase in $t / t_{r}$; the decrement of the ruptured sample was about 15 pct. The heat treatment caused little change in the hardness. Thus, the stress again had a strong effect on both the hardness change and the change in precipitates.

Figures 12(a) through (d) show TEM micrographs of the specimen exposed to the stress of $120 \mathrm{MPa}$ at $t / t_{r}=0$ (original), $0.20,0.52$, and 0.71 , respectively. The direction of stress was the horizontal direction of the photographs. The results for the ruptured sample ((a): $873 \mathrm{~K}, 120 \mathrm{MPa}, t_{r}=1925.5$ hours) and the reference sample ((b): free stress, $873 \mathrm{~K}, 2500$ hours) are also shown in Figure 13. Figure 12(a) shows many lath structures. The dislocations within the lath were observed and their density was high. Figure 12(b) shows the microstructure at the attenuation peak (Figure 8). The cell structures accounted for the majority of the area. A few subgrains were observed and their boundaries were not clear. The width of the cell was larger than in Figure 12(a). The multiplication of dislocations within the lath proceeded and the density was still high. Figure 12(c) shows the microstructure, when $\alpha$ showed its minimum. The subgrain structures accounted for the majority of the entire area. The size was larger than, and the boundaries of the subgrains were clearer than in Figure 12(b). The dislocation density within the subgrains was low. Figure 12(d) shows the microstructure at $t / t_{r}=0.71$, when $\alpha$ increased again. The entire area was covered by

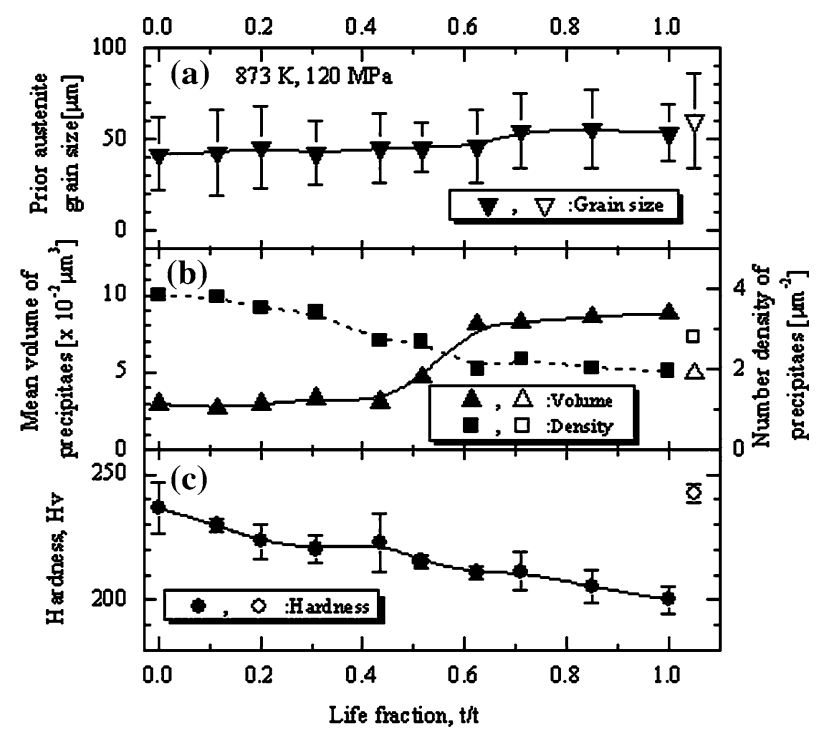

Fig. 11-Microstructure evolution in the interrupted test $(120 \mathrm{MPa}$, $873 \mathrm{~K})$ as creep progressed: $(a)$ change in the average prior austenite grain-boundary diameter, $(b)$ change in the average volume and form factor of precipitates, and $(c)$ change in the Vickers Hardness. Solid marks are data of the crept samples, and open marks are for the reference sample.

the subgrain structure. The boundaries were clearer than those in Figure 12(c). The subgrain sizes were larger than, and the dislocation density was lower than in Figure 12(c). In Figure 13(a), the subgrains and recrystallized areas were both observed. These sizes were larger than, and the dislocation density was almost the same as in Figure 12(c). Shown in Figure 13(b) is the cell structure. The cell wall became obscure in part of the area. The dislocation density was smaller than that in Figure 12(a).

We analyzed the TEM microstructures stored in the computer. For the following determination, at least five TEM micrographs from different locations on the thin foil were used. Figure 14 shows the evolution of the width of the cell or subgrains as creep progresses. As in Figure 14, the width gradually increased from the start of creep to $t / t_{r}=0.2$. It remained almost constant within the range of $t / t_{r}=0.2$ to 0.5 . Afterward, it rapidly increased with an increase in $t / t_{r}$. The width at the rupture was three times greater than before creep. In the reference sample, the width increased, but was smaller than at $t / t_{r}=0.60$. The evolution of the lath or subgrain is similar to the change in the volume of the precipitates in Figure 11(b). It was reported that the creep-strain rate was proportional to the size of the cells or subgrains multiplied by the third power, ${ }^{[43]}$ which explains the rapid increase in the size at the end of the creep life $\left(t / t_{r}>0.5\right)$. The change was strongly accelerated by the influence of the applied stress. Similar results have been reported. ${ }^{[44,45]}$ This evolution of the cell or subgrain corresponds well to the change in the attenuation coefficient in Figure 5. Finally, in Figure 15, we show the strong correlation between the hardness and width of the cells or subgrain. 


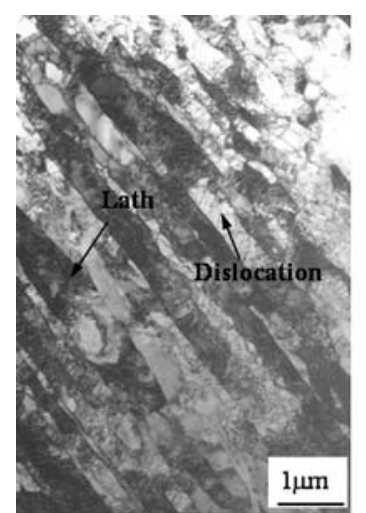

(a) $t / t=0$

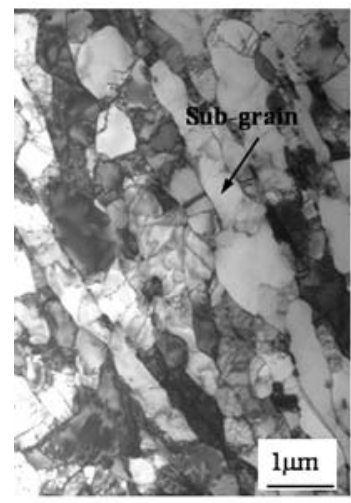

(c) $\mathrm{t} / \mathrm{t}=0.52$

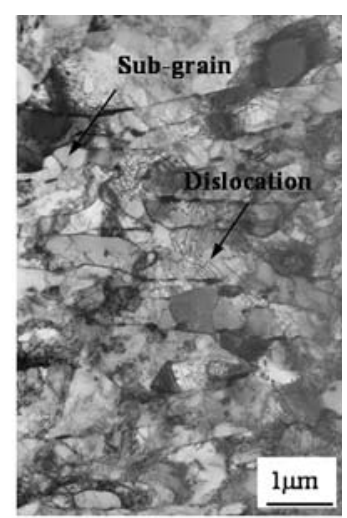

(b) $\mathrm{t} / \mathrm{t}=0.2$

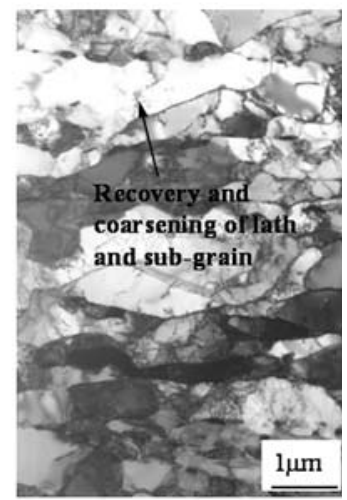

(d) $t / t=0.71$
Fig. 12- (a) through $(d)$ Transmission electron micrographs of crept specimens at $t / t_{r}=0,0.20,0.52$, and 0.71 in the interrupted test (25 MPa, $923 \mathrm{~K})$.

\section{DISCUSSION}

Possible factors contributing to the changes of the attenuation coefficient and velocity in the megahertz frequency range ${ }^{[21,46]}$ are as follows:

(a) grain scattering,

(b) scatterings caused by precipitations, and

(c) dislocation damping.

Factors of (a) and (b) were examined using the scattering theory in the Rayleigh region. ${ }^{[21,46]}$ It has been reported that they cause only negligible change in the attenuation coefficient. ${ }^{[23-28]}$ Therefore, only the dislocation damping can explain the observed acoustic response.

Dislocations vibrate in response to ultrasonic stress with a phase lag because of lattice viscosity, and part of the acoustic energy is absorbed. This inelastic mechanism also lowers the ultrasonic velocities. The dislocation lines are pinned by point defects, precipitations, grain boundaries, and other dislocations. These pinning points act as nodes of vibration of elastic strings. Granato and Lücke ${ }^{[47]}$ formulated the relationship between the attenuation coefficient and the velocity in a low frequency range as follows:

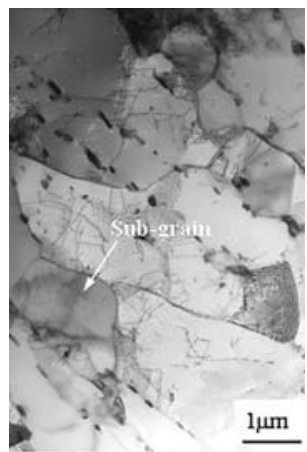

(a)

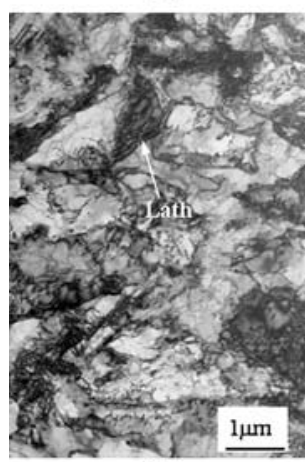

(b)

Fig. 13-Transmission electron micrographs of $(a)$ ruptured sample $\left(120 \mathrm{MPa}, 873 \mathrm{~K}, t_{r}=1925.5 \mathrm{~h}\right)$ and $(b)$ the reference sample (stress free, $873 \mathrm{~K}, 2500$-h holding).

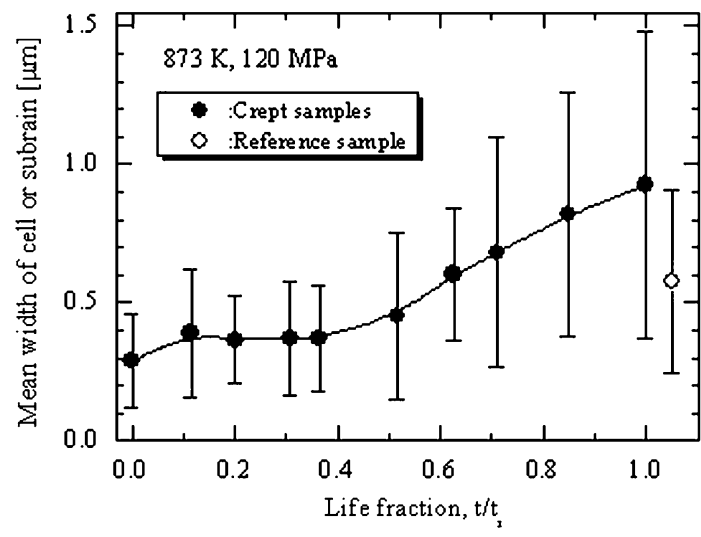

Fig. 14 - Change in the width of cells and subgrains as creep progresses in the interrupted test $(120 \mathrm{MPa}, 873 \mathrm{~K})$. Solid marks are data of the crept samples, and open marks are for the reference sample.

$$
\begin{gathered}
\alpha=C_{1} \Lambda L^{4} f^{2} \\
\left(V-V_{0}\right) / V_{0}=-C_{2} \Lambda L^{2}
\end{gathered}
$$

where $C_{1}$ and $C_{2}$ are positive constants, $V_{0}$ the velocity corresponding to the true modulus $\left(=(\mathrm{G} / \rho)^{1 / 2}, \mathrm{G}\right.$ is the shear modulus, and $\rho$ the density), $\Lambda$ the disloca- 
tion density, and $L$ the average length of the dislocation segments. According to this model, $\alpha$ is proportional to $\Lambda$, and the fourth power of the segment length $L$ of the effective dislocations and velocity is proportional to $\Lambda$ and the square of $L$, which are moveable with the ultrasonic stress. The increases in $\Lambda$ and $L$ lead to the decrease in velocity. Note that not all dislocations can interact with ultrasonics. We define these interacting dislocations as mobile dislocations, which cause changes in the ultrasonic attenuation. $\mathrm{Pa}$ hutova and $\mathrm{Cadek}^{[48]}$ also defined these dislocations as free dislocations (dislocations unbounded in subboundaries and arranged in a three-dimensional dislocation network). Dislocations piling up against grain boundaries or sub-boundaries cannot vibrate and contribute to $\alpha$. It was clear that the attenuation coefficient with EMAR clearly enabled the detection of the dislocation structure evolution in the fatigue progress of pure copper and low-carbon steel ${ }^{[49-52]}$ and in the creep progress of a $\mathrm{Cr}-\mathrm{Mo}-\mathrm{V}, 2.25$ pct $\mathrm{Cr}-1$ pct $\mathrm{Mo}$, Ni-based superalloy and austenite stainless steels. ${ }^{[23-28]}$ One expects that the attenuation in a type- 403 tempered martensitic steel changes because the dislocation structure changes during the creep.

Figure 16 shows the results obtained by the digital image analysis of the TEM micrographs. For the following determination, at least five TEM micrographs from different locations on the thin foil were used. Figure 16 shows the dislocation density, $\Lambda_{1}$, and the average dislocation length, $L_{1}$. The density of dislocations was measured with the method proposed by Keh and Weissmann. ${ }^{[53]}$ Only the dislocations pinned by carbides in grains and other dislocations, as well as movable dislocations, were considered. As shown in Figure 14, $\Lambda_{1}$ increases until $t / t_{r}=0.2$ and then decreases until the rupture. On the other hand, $L_{1}$ increases until $t / t_{r}=0.2$. Within the range of $t / t_{r}=0.2$ to $0.5, L_{1}$ remains almost constant. Afterward, $L_{1}$ increases with an increase in $t / t_{r}$. The change in $L_{1}$ is similar to the evolution of the cell and subgrain in Figure 14. The change in the dislocation structure and free dislocation density can be found in the past. ${ }^{[4-51]}$

The attenuation coefficient was given by substituting $L_{1}$ and $\Lambda_{1}$ for $L$ and $\Lambda$ in Eqs. [2] and [3]. We compared the calculated and measured attenuation coefficients and relative velocity of the fourteenth resonant mode at $120 \mathrm{MPa}$ in Figure 17, based on an assumption that: $\Lambda_{1}$ $\propto \Lambda$ and $L_{1} \propto L$, as shown in Figure 14. The constants $C_{1}$ and $C_{2}$ were determined so that the measured and the calculated $\alpha \mathrm{s}$ and $\Delta V / V_{i} \mathrm{~s}$ were consistent with each other before creep. Theoretically, the terms $\Lambda$ and $L$ are the density and length of dislocations that vibrate with ultrasonic waves (on the order of $0.1 \mathrm{~nm}$ or less in amplitude), and they are not exactly equal to the values of $L_{1}$ and $\Lambda_{1}$. It is impossible to identify which dislocations in the TEM image actually oscillated with the ultrasonic waves. In general, point defects are absorbed and pinned on dislocation lines. The distance between the point defects corresponds to $L$, which means that $L_{1}$ exceeds $L$. We considered the interaction of the point-defect pinning dislocations and assumed that longer dislocation lines would provide longer

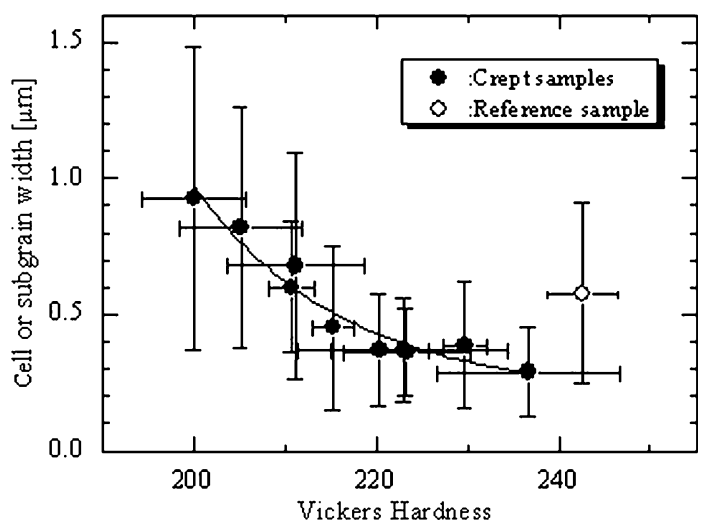

Fig. 15-Relationship between the hardness and size of the cells or subgrains as creep progresses in the interrupted test (120 MPa, $873 \mathrm{~K})$.

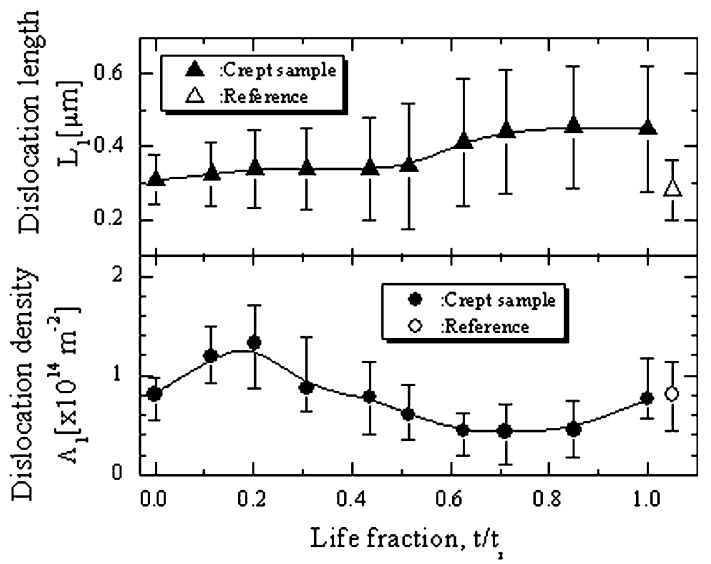

Fig. 16 - Change in the dislocation density and length as creep progresses $(120 \mathrm{MPa}, 873 \mathrm{~K})$. Solid marks are data of the crept samples, and open marks are for the reference sample.

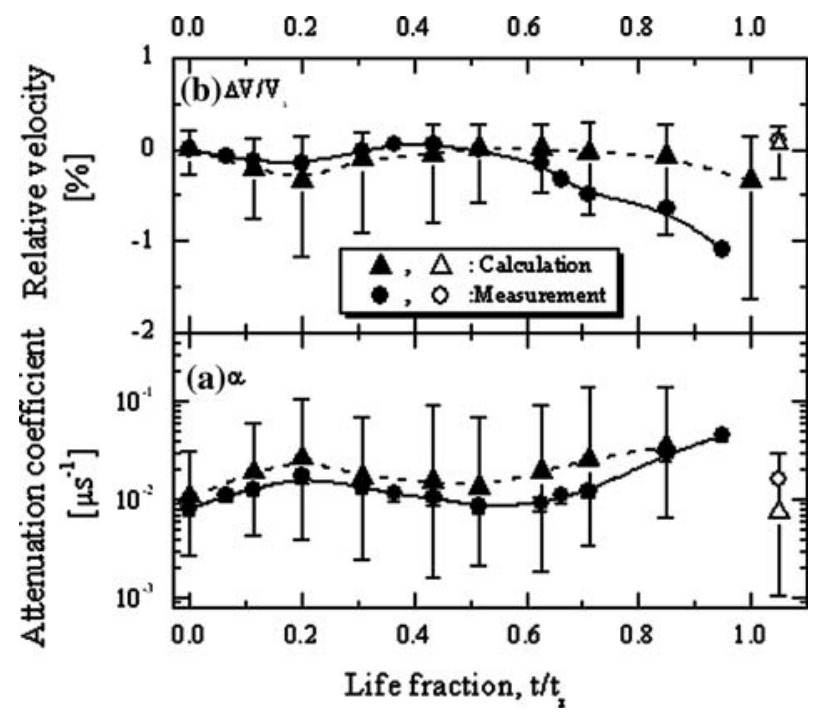

Fig. 17-Comparison between calculated and measured (a) attenuation coefficients and $(b) \Delta V / V_{i}$ in the 14 th resonant mode $(120 \mathrm{MPa}$, $873 \mathrm{~K}$ ). Solid marks are data of the crept samples and open marks are for the reference sample. 
distances between the point defects. In Figure 17, the calculated and measured $\alpha$ 's and $\Delta V / V_{i}$ 's show similar behavior. Similar to the case of a Cr-Mo-V steel, ${ }^{[28]}$ it is demonstrated that this assumption is valid, and the changes of attenuation and velocity result from the energy absorption caused by the dislocations. Figure 17 shows, however, that the absolute values of the calculated attenuation coefficient and velocity are different from those measured. It is suggested that these differences arise from the difference between $L_{1}$ and $L$, since $L$ affects $\alpha$, as shown in Eqs. [2] and [3]. Thus, the attenuation and velocity mainly change from dislocation restructuring.

Now, we intend to explain the changes in the ultrasonic properties during creep progression by dividing the response into three stages, as shown in Figure 4. From the creep-strain rate, $\dot{\varepsilon}$, stage I corresponds to the primary creep, stage II to the secondary creep, and stage III to the tertiary creep.

(a) Stage I $\left(0<t / t_{r}<0.2\right)$ : The decrease in the number density of precipitates and the increase in the cell or subgrain width start from just after the beginning of creep. Meanwhile, the coarsening and coalescence of precipitates do not occur in this stage (Figure 11). Dislocation restructuring starts and the structure changes from the lath to the subgrain. During this stage, the density of free dislocation increases (increase in $\Lambda$ ). The increases in the lath width (increase in $L$ ) cause a decline in the hardness (softening). As a result, the increases in $\Lambda$ and $L$ induce the increase in $\alpha$ and the decrease in velocity.

(b) Stage II $\left(0.2 \leq t / t_{r}<0.5\right)$ : As creep progresses, the total dislocation density further increases. The precipitates show little coarsening and coalescence and their number density still increases. The formation of subgrains becomes very active. Dislocations during stage I are largely restricted to the sub-boundaries. Then the multiplied dislocations are continuously consumed by the formation of subgrains. Their sizes increase slowly. The dislocation density on the sub-boundaries increases, but the density in the interior decreases. Therefore, the free dislocation density becomes low. As a result, $\alpha$ begins to decrease sharply and shows the peak. The velocity starts to increase slightly. At the peak of $\alpha$ and a local minimum of velocity, the creep strain is about 2 pet and $t / t_{r}$ is around 20 pet of creep life. In this stage, the work-hardening and recovery are balanced. (c) Stage III $\left(t / t_{r} \geq 0.5\right)$ : In this stage, $\dot{\varepsilon}$ increases rapidly. The coarsening and coalescence of precipitates suddenly advance. The coarsening and coalescence induce decreases in the solid-solutions (carbons) and pinning points (carbon atoms) on the dislocation lines. As a result, the distances between the pinning points become larger, and the smooth movement of the dislocations is enabled. The coarsening and coalescence cause an increase in $L$. The enlargement of the subgrain width is accelerated and advances the softening (Figure 11). As creep progresses further, the total dislocation density increases and internal energy increases. The formation of subgrains is accelerated and recrystallization is triggered by the increase in the energy. ${ }^{[54,55]}$ Furthermore, the coarsened precipitates also prompt the formation of subgrains and recrystallization. $^{[55]}$ As a result, a decrease in $\Lambda$ and an increase in $L$ cause an increase in $\alpha$ and a rapid decrease in velocity. At the minimum of $\alpha$, the creep strain is about 4 pet, and $t / t_{r}$ is around 50 pct. After that, $\alpha$ increases and the velocity decreases to the rupture. Therefore, the minimum of $\alpha$ corresponds to the point at which the width of the cell and the subgrain increases rapidly and the coarsening and coalescence of precipitates suddenly progresses.

The increase in $\alpha$ at around 20 pct of the lifetime corresponds to the start of the secondary creep and recovery, and the recovery, and the minimum at $50 \mathrm{pct}$ of the lifetime, is parallel to the start of tertiary creep. As for $2.25 \mathrm{Cr}-1 \mathrm{Mo}$ steel, $\mathrm{Cr}-\mathrm{Mo}-\mathrm{V}$ steel, Ni-based superalloy, and stainless steels, ${ }^{[23-28]}$ the peak and minimum values of the attenuation and local minimum of the velocity were observed in the creep progression of quite different materials under the different test conditions. Shown in Table III is $t / t_{r}$, where the attenuation shows the peak and the minimum in these materials. This demonstrates the universality of the EMAR method. In addition, the method is capable of capturing the microstructural evolution, dislocation mobility, and transition of the dislocation structure during the creep progression.

\section{CONCLUSIONS}

The precise measurement of the velocity and the ultrasonic attenuation coefficient during creep progress of a tempered martensitic stainless steel, type-403, was

Table III. Life Fraction at Attenuation Peak and Minimum in Some Materials

\begin{tabular}{|c|c|c|c|c|c|c|}
\hline Materials & $\begin{array}{c}\text { Type } 403 \\
\text { Stainless Steel }\end{array}$ & $\begin{array}{l}\text { Cr-Mo-V } \\
\text { Steel }\end{array}$ & $\begin{array}{c}2.25 \mathrm{Cr}-1 \mathrm{Mo} \\
\text { Steel }\end{array}$ & $\begin{array}{c}\text { 304-Type } \\
\text { Stainless Steel }\end{array}$ & $\begin{array}{c}\text { 316L-Type } \\
\text { Stainless Steel }\end{array}$ & Waspaloy \\
\hline$t / t_{r}$ at attenuation peak & 0.2 to 0.3 & 0.25 to 0.30 & 0.50 to 0.60 & 0.30 to 0.40 & 0.60 to 0.70 & 0.35 to 0.40 \\
\hline$t / t_{r}$ at attenuation minimum & 0.5 & 0.5 & 0.75 & 0.7 & 0.85 & - \\
\hline Temperature $(\mathrm{K})$ & 873 & 923 & 923 & 973 & 973 & 1073 \\
\hline Stress (MPa) & $120,140,160$ & $25,35,45,55$ & 45,65 & 100,120 & $100,110,120$ & $140,150,160$ \\
\hline Type of specimen & plate & cylindrical plate & cylindrical & plate & plate & plate \\
\hline
\end{tabular}


achieved by the high sensitivity and noncontacting aspects of EMAR. Shear-wave attenuation always showed a peak at around 20 pct and a minimum at 50 pct of the lifetime; the velocity always showed a local minimum at around $20 \mathrm{pct}$, independent of the applied stress. This observation was first made possible with the EMAR method. We interpreted these phenomena in terms of dislocation mobility and restructuring, with support from the SEM and TEM observations. The attenuation peak and the local minimum of the velocity exhibit a characteristic event, at which the recovery starts. The minimum value of the attenuation indicates the start of the tertiary creep and corresponds to the enlargement of subgrain size and the coarsening and coalescence of precipitates. The relationship between the changes in the ultrasonic attenuation and the velocity and the microstructure change can be explained with the Granato-Lücke string model. The attenuation coefficient and velocity correlate well with the creep-life fraction, but not with the creep strain and time. The change in hardness during creep is closely connected to the evolution in the width of the cell or subgrains. More accurate damage evaluation and life prediction can be achieved through the monitoring of both the attenuation coefficient and the velocity. The assessment of the damage advance and the prediction of the remaining creep life of metals may potentially be facilitated by EMAR.

\section{REFERENCES}

1. R. Viswanathan: Damage Mechanism and Life Assessment of High Temperature Components, ASM INTERNATIONAL, Materials Park, OH, 1989, pp. 1-110.

2. R.B. Dooley and R. Viswanathan: Life Extension and Assessment of Fossil Power Plants, Proc. Conf. in Washington, June 1986, EPRICS5208, Electric Power Research Institute, Palo Alto, CA, 1987.

3. B. Raj, V. Moorthy, T. Jayakumar, and R.K. Bhanu Sankara: Int. Mater. Rev., 2003, vol. 48, pp. 273-32.

4. G. Dobmann, N. Meyendorf, and E.E. Schneider: Nucl. Eng. Des., 1997, vol. 171, pp. 95-112.

5. D.S. Drion, P.K. Liaw, and R.D. Rishel: ASME PVP-Vol.239/ MPC-Vol.33, Serviceability of Petroleum Process and Power Equipment, ASME, OH, 1992, pp. 5-14.

6. P. Auerkari and J. Salonen: Int. J. Pressure Vessel Piping, 1989, vol. 39, pp. 135-44.

7. R. Becker, G. Dobmann, M. Kronig, H. Reiter, and E. Schneider: Int. J. Pressure Vessel Piping, 1997, vol. 73, pp. 11-17.

8. B. Neubauer and U. Wedel: in Advances in Life Prediction Methods, D.A. Woodford and J.R. Whitehead, eds., ASME, New York, NY, 1983, pp. 307-14.

9. R.T. Delong: ASTM standard E12-87, ASTM, Philadelphia, PA, 1987.

10. P.L. Jones and A.S. Tetelman: Eng. Fract. Mech., 1979, vol. 12, pp. $79-97$.

11. A. Garzillo, C. Guardmagna, L. Moscotti, and L. Ranzani: Int. J. Pressure Vessel Piping, 1996, vol. 663, pp. 223-32.

12. H. Willems, W. Bendick, and H. Weber: in Nondestructive Characterization of Materials II, J.F. Brussiere, J. Ruud Monchalin and R.E. Green, Jr., eds., Plenum Press, New York, NY, 1987, pp. $451-45$.

13. H.M. Ledbetter, R.J. Fields, and S.K. Datta: Acta Metall., 1987, vol. 35 , pp. $2393-98$
14. M. Nakashiro, H. Yoneyama, and A. Ohtomo: Int. Conf. on Advances in Material Technology for Fossil Power Plants, ASME International, Metals Park, OH, 1987, pp. 351-35.

15. S. Kishimoto, N. Shinya, S. Matsumoto, and H. Fukuhara: Proc. 26th Symp. on Strength of Materials at High Temperatures, The Society of Materials Science, Tokyo, 1988, pp. 11-15 (in Japanese).

16. A.S. Birring, D.G. Alcazer, J.J. Hanley, and S. Gehl: in Review of Progress in Quantitative Non-Destructive Evaluation, D.O. Thompson and D.E. Chimenti, eds., Vol. 8B, Plenum Press, New York, NY, 1989, pp. 1833-40.

17. M. Hirao, T. Morishita, and H. Fukuoka: Metall. Trans. A, 1990, vol. $21 \mathrm{~A}$, pp. $1725-32$.

18. T. Morishita and M. Hirao: Int. J. Solids Struct., 1997, vol. 34, pp. $1169-75$

19. K. Goebbels: Research Technology in NDT, Vol. 4, Academic Press, London, 1980, pp. 87-157.

20. M. Hirao, H. Ogi, and H. Fukuoka: Rev. Scientific Instrum., 1993, vol. 64, pp. 3198-3205.

21. M. Hirao and H. Ogi: Ultrasonics, 1997, vol. 35, pp. 413-21.

22. M. Hirao and H. Ogi: EMATs for Science and Industry, Kluwer Academic Publisher, Boston, MA, 2003, pp. 1-193.

23. T. Ohtani, H. Ogi, and M. Hirao: Metall. Mater. Trans. A, 2005, vol. 36A, pp. 411-20.

24. T. Ohtani, H. Ogi, and M. Hirao: Int. J. Solids Struct., 2005, vol. 42, pp. $2911-28$

25. T. Ohtani: Metall. Mater. Trans. A, 2005, vol. 36A, pp. 2967-77.

26. T. Ohtani, H. Ogi, and M. Hirao: Trans. ASME, J. Eng. Mater. Technol., 2006, vol. 128, pp. 234-42.

27. T. Ohtani, H. Ogi, and M. Hirao: Jpn. J. Appl. Phys., 2006, vol. 45 (5B), pp. 4526-33.

28. T. Ohtani, H. Ogi, and M. Hirao: Acta Mater., 2006, vol. 54, pp. $2705-13$

29. ASM Specialty Handbook, Stainless Steel, J.D. Davis, ed., ASM INTERNATIONAL, Metals Park, OH, 1994, pp. 14-18.

30. B.W. Maxfield and C.M. Fortuko: Mater. Eval., 1983, vol. 11, pp. $1399-1408$.

31. A. Wilbrand: in Review of Progress in QNDE, Plenum Press, New York, NY, 1987, vol. 7A, pp. 671-80.

32. R.B. Thompson: in Physical Acoustics, R.N. Thurston and A.D. Pierce, eds., Vol. XIX, Academic Press, Inc, New York, NY, 1990, pp. 157-200.

33. C.M. Furtunko, G.L. Petersen, B.B. Chick, M.C. Renken, and A.L. Peris: Rev. Scientific Instrum., 1992, vol. 63, pp. 3477-86.

34. H. Ogi, M. Hirao, and T. Honda: J. Acoust. Soc. Am., 1995, vol. 98, pp. 458-64.

35. K. Maruyama, C. Harada, and H. Oikawa: J. Soc. Mater. Sci. Jpn., 1985, vol. 34, pp. 1289-95.

36. K. Maruyama and H. Oikawa: Trans. ASME, J. Pressure Vessel Technol., 1987, vol. 109, pp. 142-48.

37. T. Matsuo, T. Kisanumki, R. Tanaka, and S. Komatsu: Tetsu-toHagané, 1984, vol. 70, pp. 565-72 (in Japanese).

38. G. Eggeler, N. Nilsvang, and B. Ilschner: Steel Res., 1987, vol. 47, pp. $97-103$.

39. H.R. Tipler and B.E. Hopkins: Met. Sci., 1976, vol. 10, pp. 47-53.

40. F. Abe: Mater. Sci. Eng A., 2004, vols. 387-389, pp. 565-69.

41. J. Cadek: Metallic Materials, Elsevier, Amsterdam, 1988, pp. 95-114.

42. G. Eggeler: Acta Metall, 1989, vol. 37, pp. 3225-34.

43. O.D. Sherby, R.D. Klundt, and A.K. Miller: Metall. Trans. A, 1977, vol. 8A, pp. 843-50.

44. S.V. Raj and G.M. Pharr: Mater. Sci. Eng., 1986, vol. 81, pp. $217-$ 37.

45. A. Orlova, J. Bursik, K. Kucharova, and V. Sklenicka: Mater. Sci. Eng., 1998, vol. A245, pp. 39-48.

46. R.C. Truell, C. Elbaum, and B.B. Chick: Ultrasonic Methods in Solid State Physics, Academic Press, New York, NY, 1969, pp. 159-249.

47. A. Granato and K. Lücke: J. Appl. Phys., 1956, vol. 27, pp. 58393.

48. M. Pahutova and J. Cadek: Mater. Sci. Eng., 1984, vol. 62, pp. 3340.

49. M. Hirao, H. Ogi, N. Suzuki, and T. Ohtani: Acta Mater., 2000, vol. 48 , pp. $517-24$.

50. T. Ohtani, H. Ogi, and M. Hirao: J. Alloy Compounds, 2000, vol. 310, pp. 440-44. 
51. H. Ogi, Y. Minami, and M. Hirao: J. Appl. Phys., 2002, vol. 91, pp. $1849-54$.

52. T. Ohtani, K. Nishiyama, S. Yoshikawa, H. Ogi, and M. Hirao: Mater. Sci. Eng. A., 2006, vol. 442, pp. 466-70.

53. A.S. Keh and S. Weissmann: in Electron Microscopy and Strength of Crystals, G. Thomas and J. Washburn, eds., Interscience, New York, NY, 1963, pp. 231-99.
54. C.R. Barrett, W.D. Nix, and O.D. Sherby: Trans. ASM, 1966, vol. 59, pp. 3-15.

55. T. Hasegawa, Y. Ikeuch, and S. Karashima: Met. Sci. J., 1972, vol. 6 , pp. $78-82$. 